\title{
Oral colonization by Streptococcus mutans and its association with the severity of periodontal disease in adults
}

\author{
Contardo MS ${ }^{1}$, Díaz N², Lobos O3, Padilla C ${ }^{3}$, Giacaman RA
}

\begin{abstract}
Background: Streptococcus mutans (S. mutans) is associated with the onset of caries. Since root exposure in patients affected by periodontitis leads to higher caries rates, progressively more severe forms of periodontal disease might associate with elevated counts of $S$. mutans. Aim: To determine whether increasingly destructive forms of periodontal disease are associated with higher counts of $S$. mutans in untreated patients. Methods: 206 subjects aged 20-75 were classified into three groups according to the severity of periodontal disease: 1) gingivitis, 2) chronic slight periodontitis and 3) chronic moderate or chronic severe periodontitis. S. mutans counts $(\mathrm{cfu} / \mathrm{mL})$ were obtained by direct counting on selective agar plates from saliva samples. A cumulative proportional logistic regression model was adjusted for $S$. mutans counts. Results: The model failed to show differences by gender, but periodontal diagnosis had a significant effect on S. mutans counts depending on age. While in the group with moderate and severe periodontitis the probability of having high counts of $S$. mutans significantly increased with age, the probability remained unchanged in individuals with chronic slight periodontitis or gingivitis. Conclusion: High S. mutans levels appear directly co-associated with increased severity of periodontal disease at older ages in untreated patients.
\end{abstract}

Rev. Clin. Periodoncia Implantol. Rehabil. Oral Vol. 4(1); 9-12, 2011.

Key words: Periodontitis, periodontal disease severity, Mutans Streptococci, Streptococcus mutans, caries, root caries.

\section{INTRODUCTION}

Oral biofilms usually comprise beneficial microorganisms for the host as they exclude colonization by pathogenic species ${ }^{(1,2)}$. Under certain circumstances, however, oral environmental changes may modify the composition and metabolic activities of the bacterial consortium leading to predominance of pathogens ${ }^{(1)}$. High counts of Mutans streptococci (MS), Streptococcus mutans (S. mutans) and Streptococcus sobrinus, have been associated with higher prevalence of coronal caries in temporary and permanent dentitions ${ }^{(3-7)}$ and also root caries ${ }^{(8-11)}$. In spite of the widely acknowledged association between increased levels of $M S$ and higher caries experience, other studies have argued against this association ${ }^{(12,13)}$. Colonization and pathogenicity of these facultative Gram(+) cocci derive from their capacity to synthesize extracellular polysaccharides ${ }^{(14)}$. Indeed, adult subjects colonized by biofilm-forming $S$. mutans strains have higher caries experience than individuals without these types of strains ${ }^{(12)}$.

It remains unclear whether $S$. mutans increases colonization during periodontitis. Studies have shown, on the one hand, that gingival inflammation does not associate with higher levels of $S$. mutans ${ }^{(15)}$ and higher recoveries of the microorganism have been found in treated periodontal patients during follow-up ${ }^{(5,16)}$. Likewise, periodontally treated subjects show more $S$. mutans than untreated controls ${ }^{(11)}$. Recent studies, however, report that untreated patients with periodontitis have high recovery rates of $S$. mutans from saliva, tongue dorsum, buccal mucosa and supra and subgingival plaque ${ }^{(17)}$. Moreover, studies assessing the biofilm composition of root caries have reported more elevated counts of $S$. mutans when compared with sound root surfaces ${ }^{(10)}$. Given the high prevalence of root caries in periodontally treated patients with root exposure(18), it has been hypothesized that high levels of $M S$ may act as a predictor for the onset of carious lesions in this type of patients ${ }^{(11)}$. Indeed, more root caries have been described during the follow-up of periodontally treated patients with elevated counts of $S$. mutans than those with lower number of the microorganism ${ }^{(19)}$.

The aforementioned evidence allows speculating that untreated periodontal patients with more severe forms of periodontitis, who in many cases show more root exposures, might have more cariogenic flora than those subjects with milder periodontitis or gingivitis. An association between $S$. mutans colonization and the severity of periodontal disease has not been reported. The aim of this cross sectional study was, therefore, to compare salivary $S$. mutans counts in untreated patients with gingivitis and different degrees of severity of periodontal disease.

\section{MATERIALS AND METHODS}

Subjects. 206 patients (53 males and 153 females) between 20 and 75 years-old were randomly selected to participate in the study. Patients included had to refrain from eating, rinsing or smoking two hours before the exam. Likewise, participants could not be under antibiotics therapy or oral antimicrobials at the moment of the exam. Sample size represented all the adult patients under treatment at the time of the study who met the eligibility criteria for the study protocol. Patients were chosen among those requesting dental treatment at the Dental Clinics of the University of Talca, Talca, Chile. Participants signed an informed consent form to enroll the study, which was approved by the ethics committee of the University of Talca. A comprehensive dental examination was carried out by dental students in all the patients, including radiographs. To be eligible for the study, participants must be older than 20 years old, not have been treated for periodontitis, have at least $25 \%$ of their teeth in the mouth, have a gingival index (Löe and Silness) at least of 1 and hygiene index (Silness and Löe) lower than $50 \%$. Two previously calibrated and experienced periodontists (Dr. S. Matus and Dr. M. Nally) examined the patients and verified the accuracy of the student's first diagnosis. Periodontal diagnosis criteria were based on the classification of the American Academy of Periodontology ${ }^{(20)}$. Individuals were classified as having gingivitis or periodontitis. The latter was subsequently divided into two categories according to the severity of the disease. Diagnostic categories were defined based on the level of attachment loss, as follows:

1) $0 \mathrm{~mm}$ : gingivitis associated with dental plaque only (gingivitis) $(n=92)$,

2) 1-2 mm: generalized chronic slight periodontitis (CSP) $(n=56)$ and 3) Generalized chronic moderate $(3-4 \mathrm{~mm})$ or severe (5 or more $\mathrm{mm}$ ) periodontitis (CMSP) $(n=58)$.

1. Departmento de Rehabilitación Buco-máxilofacial. Universidad de Talca, Chile.

2. Instituto de Matemática y Física. Universidad de Talca, Chile.

3. Departamento de Microbiología. Universidad de Talca, Chile.

Correspondence author: Rodrigo A. Giacaman, CD, PhD. giacaman@utalca.cl. Escuela de Odontología. Universidad de Talca. Chile. Trabajo recibido el 07/01/2011. Aprobado para su publicación el 01/04/2011.

Financing: Esta investigación fue enteramente financiada con recursos institucionales del Departamento de Rehabilitación Buco-máxilofacial de la Universidad de Talca. Los autores no declaran conflicto de interés. 


\section{S. mutans Culture and Counts}

To obtain the number of colonies of $S$. mutans, each patient chewed a piece of paraffin wax for 2 min and expectorated the saliva into sterile glass tubes. Immediately after samples were collected, saliva was homogenized for 30 seconds, diluted 1:1000 (v/v) in sterile distilled water and an aliquot of $50 \mu \mathrm{L}$ sowed on selective Trypticase-yeast-cysteinesucrose-bacitracin agar plates (TYCSB) (Merck, Darmstadt, Germany) modified by addition of $20 \%$ sucrose (w/v) (Merck, Darmstadt, Germany) for S. mutans, as described ${ }^{(13)}$. Plates were incubated at $37^{\circ} \mathrm{C}$ for $48 \mathrm{~h}$ in anaerobic jars (Gen Box Anaer; bioMérieux, Marcy-l'Etoile, France), followed by phenotypical colony identification, considering as $S$. mutans only those adherent, irregular and sugar grain-like colonies, as described elsewhere ${ }^{(21)}$. Colonies growing on the plates were counted adjusting for the dilutions to obtain the final number of $S$. mutans expressed as cfu/mL. Counts of $S$. mutans were grouped into three categories: $<1 \times 10^{5} ; 1 \times 10^{5}$ to $1 \times 10^{6}$ and $>1 \times 10^{6} \mathrm{cfu} / \mathrm{mL}$.

\section{Statistical Analysis}

Using two cut-off points, Cochran-Armitage test for trend was used to determine whether the proportion of patients with $>1 \times 10^{5} \mathrm{cfu} /$ $\mathrm{mL}$ or $>1 \times 10^{6} \mathrm{cfu} / \mathrm{mL}$ followed a linear trend with increasing severity of periodontal disease. Moreover, a proportional cumulative risk logistic regression model was adjusted to evaluate the effect of gender, age and periodontal diagnosis on the number of $S$. mutans, divided into three counting categories: $<1 \times 10^{5} ; 1 \times 10^{5}$ to $1 \times 10^{6}$ and $>1 \times 10^{6} \mathrm{cfu} / \mathrm{mL}$, with a significance level of $5 \%$.

\section{RESULTS}

The study group of patients consisted of $74.3 \%$ of females and $25.7 \%$ males. $44.7 \%$ of the participants were diagnosed with gingivitis, $27.2 \%$ with CSP and $28.2 \%$ were classified as having CMSP (Table 1 ). Median age of the participants was 34.5 years-old. Only the CSP group showed differences of age between men and women $(p=0.008)$ (Table 1).

Table 1. Patient distribution by age, gender and periodontal condition.

\begin{tabular}{|c|c|c|c|c|}
\hline & \multicolumn{2}{|c|}{ Age } & & Total \\
\hline $\begin{array}{l}\text { Periodontal } \\
\text { Diagnosis }\end{array}$ & $\begin{array}{c}\text { Male } \\
\text { Median (IQR) } \\
\text { n - \% }\end{array}$ & $\begin{array}{c}\text { Female } \\
\text { Median (IQR) } \\
\text { n - \% }\end{array}$ & $p$ value & $\begin{array}{c}\text { Median (IQR) } \\
\mathrm{n}=\%\end{array}$ \\
\hline Gingivitis & $\begin{array}{l}22.5(5.5) \\
24-45.3\end{array}$ & $\begin{array}{l}25.0(12.0) \\
68-44.4\end{array}$ & 0.084 & $\begin{array}{l}24(10.5) \\
92-44.7\end{array}$ \\
\hline $\mathrm{CSP}^{*}$ & $\begin{array}{l}33.0(12.5) \\
13-24.5\end{array}$ & $\begin{array}{l}39.0(7.0) \\
43-28.1\end{array}$ & 0.008 & $\begin{array}{l}38(9.8) \\
56-27.2\end{array}$ \\
\hline $\mathrm{CMSP}^{\star *}$ & $\begin{array}{c}43.5(12.0) \\
16-30.2\end{array}$ & $\begin{array}{c}41.5(17.3) \\
42-27.5\end{array}$ & 0.626 & $\begin{array}{c}42.0(16.3) \\
58-28.2\end{array}$ \\
\hline Total & $\begin{array}{l}30.0(18.5) \\
53-100.0\end{array}$ & $\begin{array}{c}36.0(17.0) \\
153-100.0\end{array}$ & 0.065 & $\begin{array}{l}34.5(19.0) \\
206-100\end{array}$ \\
\hline
\end{tabular}

IQR: Interquartile Range; *CSP: Chronic Slight Periodontitis; **CMSP: Chronic Moderate and Severe Periodontitis. "Mann-Whitney U test.

Cochrane-Armitage test showed that the proportion of patients with high $S$. mutans counts $\left(>1 \times 10^{6} \mathrm{cfu} / \mathrm{mL}\right)$ progressively and linearly increases from gingivitis to the two degrees of severity of periodontal disease $(p=0.0123)$ (Figure 1, solid line). When the cut-off point used was set to a level $>1 \times 10^{5} \mathrm{cfu} / \mathrm{mL}$, however, the linear trend was not observed $(p=0.8066)$ (Figure 1, dotted line).

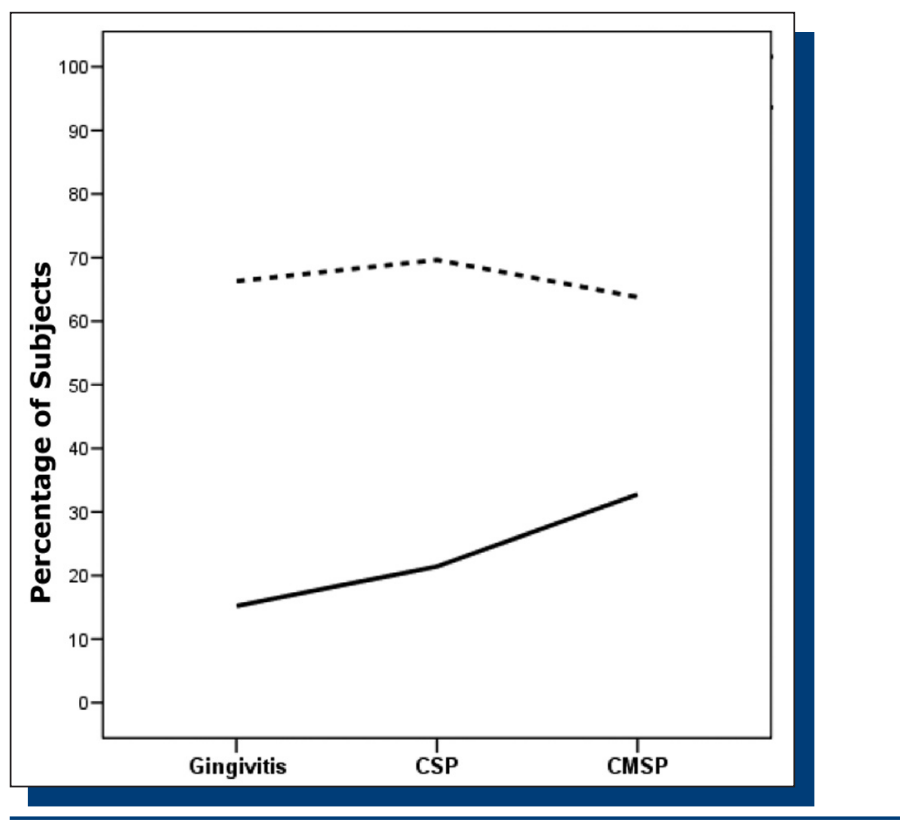

Figure 1. Cochrane-Armitage test results for patients with $S$. mutans counts $>1 \times 10^{6}$ $\mathrm{cfu} / \mathrm{mL}$ (entire line) and $>1 \times 10^{5} \mathrm{cfu} / \mathrm{mL}$ (dotted line) by periodontal condition. ${ }^{*}$ CSP: Chronic slight periodontitis.

${ }^{* *}$ CMSP: Chronic moderate and severe.

The adjusted cumulative proportional risk model for the three categories of $S$. mutans count failed to show differences by gender. By age, the model showed significant differences $(p=0.0052)$ on the microbial counts, depending on the periodontal diagnosis, nonetheless. Hence, the probability of having higher counts of $S$. mutans at older ages was significantly higher for CMSP patients when compared with CSP and gingivitis ( $p=0.0134$ and $p=0.0022$, respectively). While probability of high counts of the cariogenic species tends to increase with age in patients with CMSP (Figure 2 Panel C), the likelihood of high counts is unaffected in subjects with gingivitis and CSP (Figure 2 Panel A and B). On the other hand, probability of low counts of $S$. mutans $\left(<1 \times 10^{5}\right)$ decreases with age in CMSP (Figure 2 Panel $C$ ), but increases with age in patients with gingivitis and CSP (Figure 2 Panel A and $B$ ), without differences between the two latter diagnoses $(p=0.8087)$.

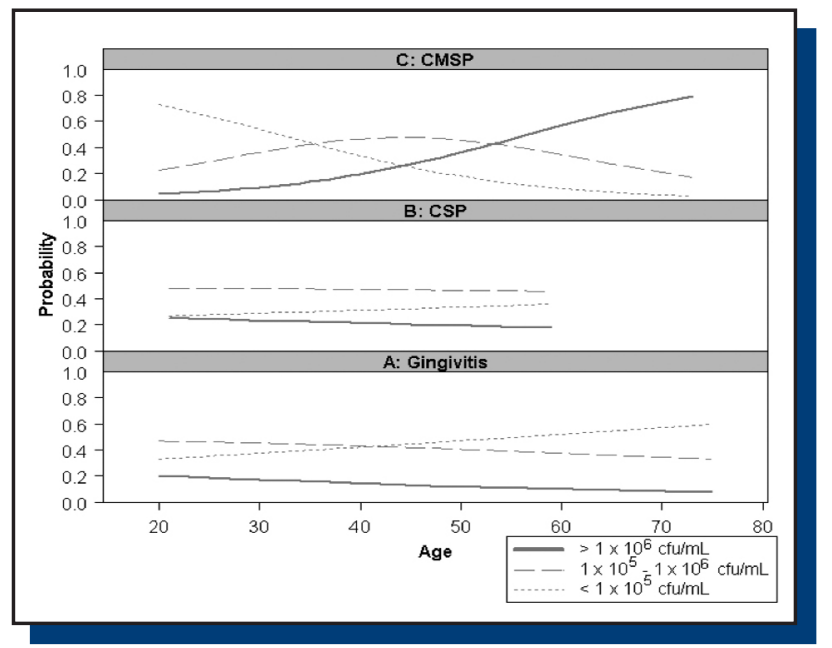

Figure 2. Adjusted cumulative proportional risk model for the probability of high, moderate and low count of S. mutans by age in gingivitis (Panel A), CSP (Panel B) and CMSP (Panel C).

*CSP: Chronic slight periodontitis.

${ }^{*}$ CMSP: Chronic moderate and severe. 


\section{DISCUSSION}

Pathogenicity of the biofilms relies, in part, on the environmental factors to which they are exposed ${ }^{(1)}$. Periodontal diseases provide substrates for bacteria that differ from those colonizing under healthy conditions $^{(22)}$. In the subgingival biofilm of less destructive forms of periodontal disease, Gram positive species, including Streptococcus and Actinomyces, are expected to be isolated ${ }^{(23)}$. Conversely, more destructive periodontitis produces periodontal pockets, which favor the establishment of anaerobic flora ${ }^{(24)}$. Based on the aforementioned issues, it is reasonable to hypothesize that more severe forms of periodontal disease create different ecological niches for the proliferation of $S$. mutans. In this study, it was found that patients with gingivitis or milder forms of periodontal disease are more likely to have low counts of $S$. mutans than subjects with more severe forms of periodontitis, who showed significantly higher counts of the cariogenic species, in both cases, in an age-dependent manner (Figure 2).

It has been reported that microbial flora changes after periodontal therapy, from one more predominantly periodontopathogenic to one more cariogenic ${ }^{(11,25)}$. Despite the changes in proportion of $S$. mutans before and after the therapy, the bacterium persists within the biofilm of the treated patients ${ }^{(16)}$. Microbiological changes due to periodontal treatment may affect the incidence of caries, particularly root caries. Periodontally treated patients show higher rates of root caries, even over $80 \%$, which is higher in subjects with high counts of S. mutans ${ }^{(19)}$. $S$. mutans has been isolated more frequently from root caries than from non-carious root tissues and it is believed to participate in the etiology of the lesions ${ }^{(8-10,26)}$. Whether there is an association between progression of periodontal disease and a higher proportion of $S$. mutans has not been reported. Importantly, our study was performed from saliva rather than from root surfaces samples. S. mutans in saliva characterizes the overall colonization by the microorganism, but it may misrepresent the presence of the bacterium on the root surfaces or in the carious lesions. Further studies must consider this issue in their experimental design.

A higher presence of $S$. mutans in untreated patients with chronic moderate or severe periodontitis, as we show here, may derive from a lower oxygen tension within the periodontal pockets ${ }^{(27)}$, which favors growth of microaerophilic species, such as $S$. mutans. On the other hand, oral biofilm comprises hundreds of species coexisting in the same ecosystem ${ }^{(28-30)}$. Predominance of one species over the other may be the result of interspecies competition ${ }^{(31)}$. When one species predominates, it may exclude others and create new conditions for the remaining microorganims. Thus, in the oral biofilm multiple species can co-aggregate to colonize the tooth surface ${ }^{(32)}$, or provide nutrients to other bacteria by metabolization of substrates ${ }^{(33)}$. After cleaning the teeth, streptococci compete for colonizing saliva-coated enamel or dentin ${ }^{(34)}$, in some cases mediated by the expression of adhesion molecules ${ }^{(30)}$ or antibacterial molecules ${ }^{(2,12)}$. Periodontitis-associated microorganisms can coexist with $S$. mutans and survive acidic conditions constrained by sacarolitic flora by interspecies interactions. For example, by fermenting glutamic and aspartic acids, $F$. nucleatum y $P$. intermedia produce ammonium, which increases $\mathrm{pH}$ protecting peridontopathogens such as $P$. gingivalis ${ }^{(35)}$. It is important to state, though, that several microniches may exist in the mouth, each having different composition of species within the consortium of the oral biofilm. Lower oxygen tension in deeper periodontal pockets might exclude $S$. mutans in some of the microniches, which can explain why the differences observed are not too large when the different severities of the disease were compared. However, higher overall colonization by $S$. mutans associated with more severe periodontitis in untreated patients, measured in whole saliva, may be the result of several ecological changes in the oral environment of this type of patients. Hence, the mechanism by which $S$. mutans levels increase with severity of periodontitis, requires further investigation.

Findings of the present investigation are in line with a reported higher risk for root caries in periodontitis patients ${ }^{(36)}$. More severe forms of periodontitis at older ages might represent an increased risk for root caries, suggesting a need for more effective caries control measurements in people affected by periodontal disease.

\section{ACKNOWLEDGEMENTS}

The authors would like to thank technical staff of the Microbiology Laboratory of the University of Talca for their kind support in helping with the processing of the samples and to the dental students of fourth year at the University of Talca for facilitating patient examination and saliva sampling. This investigation was entirely funded by institutional resources from the Department of Oral Rehabilitation of the University of Talca, Chile. The authors declare no conflict of interest.

\section{REFERENCES}

1. Marsh PD. Dental plaque as a biofilm and a microbial community implications for health and disease. BMC Oral Health, 2006; 6 Suppl 1: S14. 2. Kuramitsu HK, He X, Lux R, Anderson MH, Shi W. Interspecies interactions within oral microbial communities. Microbiol Mol Biol Rev, 2007; 71: 653-670.

3. Lemos JA, Abranches J, Burne RA. Responses of cariogenic streptococci to environmental stresses. Curr Issues Mol Biol, 2005; 7: 95-107.

4. Liljemark WF, Bloomquist C. Human oral microbial ecology and dental caries and periodontal diseases. Crit Rev Oral Biol Med, 1996; 7: 180-198.

5. Loesche WJ. Role of Streptococcus mutans in human dental decay. Microbiol Rev, 1986; 50: 353-380.

6. Tanzer JM, Livingston J, Thompson AM. The microbiology of primary dental caries in humans. J Dent Educ, 2001; 65: 1028-1037.

7. Thenisch NL, Bachmann LM, Imfeld T, Leisebach Minder T, Steurer J. Are mutans streptococci detected in preschool children a reliable predictive factor for dental caries risk? A systematic review. Caries Res, 2006; 40: 366-374.

8. Fure S, Romaniec M, Emilson CG, Krasse B. Proportions of Streptococcus mutans, Lactobacilli and Actinomyces spp in root surface plaque. Scand J Dent Res, 1987; 95: 119-123.

9. Nyvad B, Kilian M. Microflora associated with experimental root surface caries in humans. Infect Immun, 1990; 58: 1628-1633.

10. Preza D, Olsen I, Aas JA, Willumsen T, Grinde B, Paster BJ. Bacterial profiles of root caries in elderly patients. J Clin Microbiol, 2008; 46: 2015-2021.

11. Quirynen M, Gizani S, Mongardini C, Declerck D, Vinckier F, Van Steenberghe $D$. The effect of periodontal therapy on the number of cariogenic bacteria in different intra-oral niches. J Clin Periodontol, 1999; 26: 322-327.
12. Giacaman RA, Araneda E, Padilla C. Association between biofilmforming isolates of mutans streptococci and caries experience in adults. Arch Oral Biol, 2010; 55: 550-554.

13. van Palenstein Helderman WH, Matee MI, van der Hoeven JS, Mikx $\mathrm{FH}$. Cariogenicity depends more on diet than the prevailing mutans streptococcal species. J Dent Res, 1996; 75: 535-545.

14. Kreth J, Zhu L, Merritt J, Shi W, Qi F. Role of sucrose in the fitness of Streptococcus mutans. Oral Microbiol Immunol, 2008; 23: 213-219.

15. Jalil RA. Correlating Streptococcus mutans counts in saliva with plaque amount, gingival inflammation and caries experience in schoo children. Singapore Dent J, 1995; 20: 16-20.

16. Van der Reijden WA, Dellemijn-Kippuw N, Stijne-van Nes AM, de Soet JJ, van Winkelhoff AJ. Mutans streptococci in subgingival plaque of treated and untreated patients with periodontitis. J Clin Periodontol, 2001; 28: 686-691.

17. Loesche WJ, Syed SA, Schmidt E, Morrison EC. Bacterial profiles of subgingival plaques in periodontitis. J Periodontol, 1985; 56: 447-456.

18. Estrela CR, Pimenta FC, Alencar AH, Ruiz LF, Estrela C. Detection of selected bacterial species in intraoral sites of patients with chronic periodontitis using multiplex polymerase chain reaction. J Appl Oral Sci, 2010; 18: 426-431.

19. Ravald N, Birkhed D. Prediction of root caries in periodontally treated patients maintained with different fluoride programmes. Caries Res, 1992; 26: 450-458.

20. Reiker J, van der Velden U, Barendregt DS, Loos BG. A cross-sectional study into the prevalence of root caries in periodontal maintenance patients. J Clin Periodontol, 1999; 26: 26-32.

21. AAP. 1999 International International Workshop for a Classification of Periodontal Diseases and Conditions. Papers. Oak Brook, Illinois, October 30-November 2, 1999. Ann Periodontol, 1999; 4: i, 1-112. 
22. van Palenstein Helderman $W H$, ljsseldijk $M$, Huis in 't Veld $J H$. A selective medium for the two major subgroups of the bacterium Streptococcus mutans isolated from human dental plaque and saliva. Arch Oral Biol, 1983; 28: 599-603.

23. Emilson CG. Prevalence of Streptococcus mutans with different colonial morphologies in human plaque and saliva. Scand J Dent Res, 1983; 91: 26-32.

24. Lovegrove JM. Dental plaque revisited: Bacteria associated with periodontal disease. J N Z Soc Periodontol, 2004: 7-21.

25. Haffajee AD, Socransky SS. Microbial etiological agents of destructive periodontal diseases. Periodontol 2000, 1994; 5: 78-111.

26. Socransky SS, Haffajee AD, Cugini MA, Smith C, Kent RL Jr. Microbial complexes in subgingival plaque. J Clin Periodontol, 1998; 25: 134-144.

27. De Soete M, Dekeyser C, Pauwels M, Teughels W, van Steenberghe $D$, Quirynen M. Increase in cariogenic bacteria after initial periodontal therapy. J Dent Res, 2005; 84: 48-53.

28. Schupbach P, Osterwalder V, Guggenheim B. Human root caries: Microbiota in plaque covering sound, carious and arrested carious root surfaces. Caries Res, 1995; 29: 382-395.

29. Hanioka T, Tanaka M, Takaya K, Matsumori Y, Shizukuishi S. Pocket oxygen tension in smokers and non-smokers with periodontal disease. $J$ Periodontol, 2000; 71: 550-554.

30. Kolenbrander PE. Oral microbial communities: Biofilms, interactions, and genetic systems. Annu Rev Microbiol, 2000; 54: 413-437.

31. Foster JS, Kolenbrander PE. Development of a multispecies ora bacterial community in a saliva-conditioned flow cell. Appl Environ Microbiol, 2004; 70: 4340-4348.
32. Kolenbrander PE, Andersen RN, Blehert DS, Egland PG, Foster JS, Palmer RJ Jr. Communication among oral bacteria. Microbiol Mol Biol Rev, 2002; 66: 486-505, table of contents.

33. Davey ME, O'Toole GA. Microbial biofilms: From ecology to molecular genetics. Microbiol Mol Biol Rev, 2000; 64: 847-867.

34. Blehert DS, Palmer RJ Jr., Xavier JB, Almeida JS, Kolenbrander PE. Autoinducer 2 production by Streptococcus gordonii DL1 and the biofilm phenotype of a lux $S$ mutant are influenced by nutritional conditions. $J$ Bacteriol, 2003; 185: 4851-4860.

35. Egland PG, Palmer RJ Jr., Kolenbrander PE. Interspecies communication in Streptococcus gordonii-Veillonella atypica biofilms: Signaling in flow conditions requires juxtaposition. Proc Natl Acad Sci, USA 2004; 101: 16917-16922.

36. Nobbs AH, Vajna RM, Johnson JR et al. Consequences of a sortase a mutation in Streptococcus gordonii. Microbiology, 2007; 153: 4088-4097. 37. Padilla C, Lobos O, Hubert E, Poblete F, Navarro A, Nunez L. In vitro antibacterial activity of the peptide PsVP-10 against Streptococcus mutans and Streptococcus sobrinus with and without glycocalyx. Int $J$ Antimicrob Agents, 2006; 27: 212-216.

38. Takahashi N. Acid-neutralizing activity during amino acid fermentation by Porphyromonas gingivalis, Prevotella intermedia and Fusobacterium nucleatum. Oral Microbiol Immunol, 2003; 18: 109-113.

39. Boehm TK, Scannapieco FA. The epidemiology, consequences and management of periodontal disease in older adults. J Am Dent Assoc, 2007; 138 Suppl: 26S-33S. 